\title{
Online Gaming During the COVID-19 Pandemic in India: Strategies for Work-Life Balance
}

\author{
Kritika Premnath Amin ${ }^{1} \cdot$ Mark D. Griffiths ${ }^{2} \cdot$ Deena Dimple Dsouza $^{3}$ \\ Published online: 10 July 2020 \\ (C) Springer Science+Business Media, LLC, part of Springer Nature 2020
}

The novel coronavirus disease 2019 (COVID-19) pandemic has brought the entire world to a relative standstill, affecting millions worldwide at the time of writing (June 24, 2020) (World Health Organization [WHO] 2020). With the absence of an effective vaccine, public health measures have been implemented by governments worldwide, such as quarantine, closing workplaces (including schools and businesses), and spatial distancing (Nussbaumer-Streit et al. 2020). To combat the spread of COVID-19, the Indian government implemented nationwide lockdown measures and self-isolation policies. In the Indian context, "lockdown" refers to individuals staying at home while completely restricting the movement of the population inside and outside of specific areas except for essential activities (health visits, purchasing for essential items, and providing essential work) (Lippi et al. 2020). As a consequence, the measures have led to occupational and educational disruption and psychological distress for many individuals.

One area that has been relatively unaffected during the pandemic is the gaming industry, with user engagement growing considerably during this period (Javed 2020). For example, WinZo Games, an Indian-based gaming company, have reported three times more user engagement and 30\% higher traffic in online mobile gaming. Around 35\% higher usage has been observed in multi-player modes in comparison with single-user modes, a trend also found elsewhere (Bora 2020). Similarly, Paytm First Games, an Indian mobile-based online gaming

Deena Dimple Dsouza

deena.dimple@manipal.edu

Kritika Premnath Amin

kritikaamin@gmail.com

Mark D. Griffiths

mark.griffiths@ntu.ac.uk

1 Plexus Neuro and Stem Cell Research Center, 503, 3rd A Main Road, 5th Cross, OMBR Layout, Banaswadi, Bangalore 560043, India

2 Psychology Department, Nottingham Trent University, 50 Shakespeare Street, Nottingham NG1 4FQ, UK

3 Department of Occupational Therapy, Manipal College of Health Professions, Manipal Academy of Higher Education, Manipal, India 
platform, reported an almost $200 \%$ increase in the user base during the pandemic, with 75,000 new users (Ahaskar 2020).

During the lockdown period, there was also an increase in user engagement in online gaming among those aged 25-35 years and a marginal increase in female users (Bora 2020). Gaming has been reported throughout the day, with a peak gaming time from 8pm until midnight (Bora 2020). The reason for the increased uptake in Indian gaming is because many people are now housebound and there are few leisure activities that individuals can participate in. To date, online gaming has played a supporting role in public health efforts to enforce effective spatial distancing during the pandemic and has been supported by the World Health Organization's collaborative campaign (\#PlayApartTogether) with the online gaming industry encouraging individuals to stay at home and limit the spread of the virus (Maden 2020).

Research evidence suggests that most engagement in gaming is of positive benefit (Griffiths 2019) and that the benefits can by educational, physical, and therapeutic (Griffiths et al. 2017). Gaming can also help in developing cognitive skills such as reasoning, spatial awareness, and problem-solving (Bowen 2014; Nuyens et al. 2019). However, excessive gaming for protracted periods can be problematic for a minority of individuals. Research evidence suggests that problematic gaming is associated with psychosocial problems such as lack of sleep, low school well-being, concentration problems, impaired life skills, and poor selfcontrol (Männikkö et al. 2020). Extreme engagement in online gaming is also strongly associated with poor academic performance among school-going children and adolescents (Terry and Malik 2018).

The literature suggests that multiple factors are associated with problematic gaming such as personality traits (Şalvarlı and Griffiths 2019), anxiety (Adams et al. 2019; Männikkö et al. 2020), entertainment achievement and escapism (Männikkö et al. 2017), game genre (Mihara and Higuchi 2017; Na et al. 2017), and sensation-seeking behaviors (Hu et al. 2017). It has also been speculated that during the COVID-19 pandemic, some individuals may develop an increasing pattern of gaming to relieve psychological distress (King et al. 2020). According to a recent Indian study, gaming behavior increased among college students in the lockdown period (Balhara et al. 2020). Also, due to the lockdown and subsequent occupational and/or educational disruption, individuals may have much more free time and/or may be easily distracted from working at home due to temptations such as online gaming. Subsequently, there is a need for well-balanced and effective strategies to support physical and psychological well-being (King et al. 2020).

Individuals usually follow a structured routine or a set of routinized behaviors. These routines can provide life satisfaction and bring more significant meaning to one's life (Heintzelman and King 2019). Given the apparent considerable increase in online gaming and the occupational and/or educational disruption it may cause for some individuals, it is important to maintain a healthy work/life balance during the COVID-19 crisis. The proposed model of lifestyle balance by Matuska and Christiansen (2008) suggests five aspects (i.e., health and physical safety; having rewarding and self-affirming relationships; feeling interested, engaged, challenged, and competent; creating meaning and positive personal identity; and organizing time and energy to meet personal goals). These and other aspects are briefly looked at in turn, in relation and gaming and occupational and/or educational balance.

Many factors, such as good nutrition, exercise, safety practices, adequate sleep, managing stress, and avoiding addictive substances, can have beneficial effects on health (Matuska and Christiansen 2008). Given the significance of spatial distancing and nationwide lockdown in India at the time of writing, participation in a variety of activities across various mediums is 
needed to maintain psychological well-being. Engaging in gaming can be time-consuming and has been associated with increased consumption of sweet drinks (Turel et al. 2017), but maintaining a healthy diet is essential. Also, excessive online gaming is associated with physical inactivity, obesity, musculoskeletal problems (pain in hands, wrist, neck, and back), and visual problems (Ayenigbara 2018; Zirek et al. 2020). At present, there is much uncertainty as to what will happen regarding the COVID-19 pandemic, due to the ever-changing characteristics of the virus (Lippi et al. 2020). This is causing immense psychological distress and fear among some individuals all over the world (Ahorsu et al. 2020; Liu et al. 2020; Pakpour and Griffiths 2020; Xiang et al. 2020). Such psychosocial effects can lead to emotional distress, anxiety, depression, substance use disorders, and behavioral addictions (Pfefferbaum and North 2020). Subsequently, engagement in gaming can be a healthy way to relieve stress and modify mood (Lee et al. 2017), especially during times of crisis. However, excessive engagement in gaming and unhealthy coping strategies can prove challenging in developing a healthy daily routine. Here, we recommend the following strategies to maintain occupational and/or educational balance in times of challenge due to lockdown following the COVID-19 pandemic.

1. Manage stress effectively - Stress management has a key impact on health and well-being, and it is important to incorporate healthy coping strategies such as regular exercise, deep breathing, yoga, or meditation in daily routines to decrease stress and elevate mood. It is vital to pay attention to the body signals, having personal time, space, and reflecting. Engagement in gaming reduces stress but it is imperative not to use this to the neglect of all other stress-relieving activities.

2. Get adequate sleep - Sleep hygiene is essential and can be helped by maintaining a sleep diary for duration and time of sleep. Individuals should (i) have a specific time they go to bed, (ii) avoid gaming before bedtime, (iii) ensure electronic gaming devices are not kept in the bedroom, and (iv) should make sure the bedroom is noise-free with dim light. Adequate sleep is important for psychological well-being and physical functioning. Optimizing circadian rhythms and managing the sleep-wake cycle contributes to enhanced energy levels.

3. Engage in physical activity - Gaming can often displace physical activity, so it is very important to engage in physical activity to elevate mood and maintain health. Physical activity is an important outcome of health and well-being. Engaging in outdoor activities, walking, gardening, jogging, and any other activity that can be done in a safe and spatially distanced way. To avoid prolonging engagement in gaming, individuals need to set time restraints for gaming, incorporate frequent breaks, stretch, maintain good posture with a straight back, keep the head and neck upright, and consciously blink eyes.

4. Engage in good nutrition and eating habits - It is very common to snack while gaming. Snacking healthy food is important, and gamers should eat meals at regular meal times (and not skip meals) and, like sleep, monitor their eating behavior.

5. Have rewarding and self-affirming relationships - Good social support and emotional support can be protective factors for maintaining an individual's good health (Reblin and Uchino 2008). Furthermore, positive relationships and social support predict life satisfaction (Siedlecki et al. 2014). However, problematic online gaming is highly associated with cyberbullying and aggression (Mcinroy and Mishna 2017), which can have a major impact on an individual's offline social relationships. Forming or renewing real social relationships is necessary. In the modern busy work schedule, individuals often find it 
hard to spend quality time with their family and socialize with friends. Capitalizing on the current situation, given that a significant proportion of the world's individuals are confined to their homes, for some it is an ideal time to reconnect with family and strengthen existing friendships. This can be done both in and outside of online gaming (Griffiths 2020). Moreover, having a socially supportive environment has been associated with psychological well-being. Family time is important; having conversations, engaging in offline games, and participating in household chores can also help reduce stress and further strengthen relationships. For children and adolescents, parents need to monitor a child's game time and encourage more engagement in offline activities.

6. Engage in challenging activities-Work is an important way of interacting with the environment, fulfilling roles and responsibility, and developing mastery, which increases the sense of competence and self-efficacy. Participating in online gaming can also enhance positive emotions and bring about happier moods (Russoniello et al. 2009) by feeling entertained (Männikkö et al. 2017). However, problematic online gaming is associated with low social competence and self-esteem (Kuss and Griffiths 2012). Therefore, it is important for individuals to invest in exploring new leisure activities and skills and/or restarting old ones to be engaged and productive. As mentioned earlier, participation in an array of physical activities, social activities, as well as cognitive-based activities with the component of challenge will be helpful. Exploration and participation in meaningful and gratifying activities such as painting, gardening, puzzles, and other activities should be encouraged.

7. Create meaning and positive personal identity - To create meaning and positive personal identity, individuals engage in a wide range of activities. During the pandemic, it is recommended that individuals be mindful when participating in gaming. Online gaming provides a platform to create a unique identity. For instance, in role-playing games, the player is free to choose gender, race, background, and physical appearance. The gaming industry has designed games and avatars, and some gamers form deep attachments to their game character (King et al. 2010). However, for a minority, there is a risk of developing internet gaming disorder (IGD) where the individual can experience physical, emotional, and self-identity disturbances (Stavropoulos et al. 2019). Even though gaming provides an opportunity to escape the present reality, it is recommended that individuals find meaning and identity in their everyday events. The COVID-19 crisis has given many individuals sufficient time to reflect on their career, goals, inspiration, motivations, and drives. Consequently, participating in a variety of activities (including physical, creative, cognitive, and expressive activities) to maintain psychological well-being and overall health is highly recommended.

8. Organize time and energy to meet personal goals - Due to the current pandemic, millions of individuals are facing an occupational and/or educational imbalance. For some, this will cause stress associated with infringement on personal freedom, complete disruption of structured routines, and engagement in activities susceptible to behavioral addiction (Pfefferbaum and North 2020). In addition, the allocation of time for day-to-day activities can become challenging and may cause occupational and/or educational disruption for individuals (Whiteford 2000). Individuals who engage in excessive gaming will find the activity time-consuming, leading to less available time to engage in other activities. This could lead to delaying or completely avoiding necessary activities. When these routines are disrupted due to excessive engagement in online gaming, it may lead to occupational and/or educational imbalance inducing stress, anxiety, and various mental health issues 
(Brown and Hollis 2013). This occupational imbalance or disruption can further lead to occupational and/or educational deprivation, paving the way to associated mental health issues. It is recommended that individuals make a more active choice of time use. Engagement in a variety of goal-directed healthy habits (which can include gaming) and maintaining positive relationships (which can be with others in and outside of gaming) is essential. It is important to plan a routine, use planners, keep a record of time spent on gaming, and using apps such as digital well-being and timers. Appropriate time use is highly related to individual well-being.

\section{Final Thoughts}

As lockdowns are eased in India and elsewhere, the minority who have used gaming as an unhealthy coping mechanism (where there is an over-dependence on gaming as a means of escapism from reality) may suffer from mental health issues. For some, the impact of the pandemic may lead to the persistence of excessive gaming and result in negative consequences. Mental health experts such as psychiatrists, psychologists, occupational therapists, and social workers must continue to monitor the psychosocial needs of individuals and deliver the needed psychosocial support wherever and whenever they can (Pfefferbaum and North 2020). The general population, especially vulnerable groups, requires the utmost mental health care during this pandemic. Early identification of the vulnerable population should begin as early as possible to help overcome the mental health issues caused by the COVID-19 pandemic.

\section{Compliance with Ethical Standards}

Conflict of Interest The authors declare that they have no conflict of interest.

Ethical Approval Not applicable.

Informed Consent Not applicable.

\section{References}

Adams, B. L. M., Stavropoulos, V., Burleigh, T. L., Liew, L. W. L., Beard, C. L., \& Griffiths, M. D. (2019). Internet gaming disorder behaviors in emergent adulthood: A pilot study examining the interplay between anxiety and family cohesion. International Journal of Mental Health and Addiction, 17(4), 828-844. https://doi.org/10.1007/s11469-018-9873-0.

Ahaskar, A. (2020). How gaming industry is fighting the battle against Covid-19. Live Mint, April 1. Retrieved June 24, 2020, from: https://www.livemint.com/news/india/how-gaming-industry-is-fighting-the-battleagainst-covid-19-11585748266505.htmlp

Ahorsu, D. K., Lin, C. Y., Imani, V., Saffari, M., Griffiths, M. D., \& Pakpour, A. H. (2020). The fear of COVID19 scale: Development and initial validation. International Journal of Mental Health and Addiction. https://doi.org/10.1007/s11469-020-00270-8.

Ayenigbara, I. O. (2018). Gaming disorder and effects of gaming on health: An overview. Journal of Addiction Medicine and Therapeutic Science, 4(1), 1-3. https://doi.org/10.17352/24553484.000025. 
Balhara, Y. P. S., Kattula, D., Singh, S., Chukkali, S., \& Bhargava, R. (2020). Impact of lockdown following COVID-19 on the gaming behavior of college students. Indian Journal of Public Health, 64(6), 172-176.

Bora, G. (2020). For Indian gaming startups, Covid-19 lockdown is a boon for business. The Economic Times, April 13. Retrieved June 24, 2020, from: https://economictimes.indiatimes.com/smallbiz/startups/newsbuzz/for-indian-gaming-startups-covid-19-lockdown-is-a-boon-forbusiness/articleshow/75115595.

Bowen, L. (2014). Video game play may provide learning, health, social benefits, review finds. Monitor on Psychology, 45(2). https://www.apa.org/monitor/2014/02/video-game.

Brown, V. H., \& Hollis, V. (2013). The meaning or occupation, occupational needs and occupational therapy in a military context. Physical Therapy, 93(9), 1244-1253. https://doi.org/10.2522/ptj.20120162.

Griffiths, M. D. (2019). The therapeutic and health benefits of playing videogames. In A. Attrill-Smith, C. Fullwood, M. Keep, \& D. J. Kuss (Eds.), The Oxford handbook of cyberpsychology (pp. 485-505). Oxford: Oxford University Press.

Griffiths, M. D. (2020). Coronavirus: Making friends through online gaming. The Conversation, March 24. Retrieved July 2, 2020, from: https://theconversation.com/coronavirus-making-friends-through-onlinevideo-games-134459.

Griffiths, M. D., Kuss, D. J., \& Ortiz de Gortari, A. B. (2017). Videogames as therapy. International Journal of Privacy and Health Information Management, 5(2), 71-96. https://doi.org/10.4018/ijphim.2017070105.

Heintzelman, S. J., \& King, L. A. (2019). Routines and meaning in life. Personality and Social Psychology Bulletin, 45(5), 688-699. https://doi.org/10.1177/0146167218795133.

Hu, J., Zhen, S., Yu, C., Zhang, Q., \& Zhang, W. (2017). Sensation seeking and online gaming addiction in adolescents: A moderated mediation model of positive affective associations and impulsivity. Frontiers in Psychology, 8, 699. https://doi.org/10.3389/fpsyg.2017.00699.

Javed, J. (2020). eSports and gaming industry thriving as video games provide escape from reality during coronavirus pandemic. Retrieved June 24, 2020, from: https://www.wfaa.com/article/sports/esports-gamingindustry-thriving-as-video-games-provide-escape-from-reality-during-coronavirus-pandemic/287-5953 d982-d240-4e2b- a2ba-94dd60a8a383.

King, D., Delfabbro, P., \& Griffiths, M. (2010). Video game structural characteristics: A new psychological taxonomy. International Journal of Mental Health and Addiction, 8(1), 90-106. https://doi.org/10.1007 /s11469-009-9206-4.

King, D. L., Delfabbro, P. H., Billieux, J., \& Potenza, M. N. (2020). Problematic online gaming and the COVID19 pandemic. Journal of Behavioral Addictions. https://doi.org/10.1556/2006.2020.00016.

Kuss, D. J., \& Griffiths, M. D. (2012). Online gaming addiction in children and adolescents: A review of empirical research. Journal of Behavioral Addictions, 1, 3-22. https://doi.org/10.1556/JBA.1.2012.1.1.

Lee, S. Y., Lee, H. K., \& Choo, H. (2017). Typology of Internet gaming disorder and its clinical implications. Psychiatry and Clinical Neurosciences, 71(7), 479-491. https://doi.org/10.1111/pcn.12457.

Lippi, G., Henry, B. M., Bovo, C., \& Sanchis-gomar, F. (2020). Health risks and potential remedies during prolonged lockdowns for coronavirus disease. Diagnisis, 7(2), 85-90.

Liu, S., Yang, L., Zhang, C., Xiang, Y.-T., Liu, Z., Hu, S., \& Zhang, B. (2020). Online mental health services in China during the COVID-19 outbreak. The Lancet Psychiatry, 7(4), e17-e18. https://doi.org/10.1016 /S2215-0366(20)30077-8.

Maden, A. (2020). World Health Organization encourages people to game during coronavirus outbreak. Windows Central, March 28. Retrieved June 24, 2020, from: https://www.windowscentral.com/worldhealth-organization-encourages-people-game-during-coronavirus-outbreak.

Männikkö, N., Billieux, J., Nordström, T., Koivisto, K., \& Kääriäinen, M. (2017). Problematic gaming behaviour in Finnish adolescents and young adults: Relation to game genres, gaming motives and self-awareness of problematic use. International Journal of Mental Health and Addiction, 15(2), 324-338. https://doi. org/10.1007/s11469-016-9726-7.

Männikkö, N., Ruotsalainen, H., Miettunen, J., Pontes, H. M., \& Kääriäinen, M. (2020). Problematic gaming behaviour and health-related outcomes: A systematic review and meta-analysis. Journal of Health Psychology, 25, 67-81. https://doi.org/10.1177/1359105317740414.

Matuska, K. M., \& Christiansen, C. H. (2008). A proposed model of lifestyle balance. Journal of Occupational Science, 15(1), 9-19. https://doi.org/10.1080/14427591.2008.9686602.

Mcinroy, L. B., \& Mishna, F. (2017). Cyberbullying on online gaming platforms for children and youth. Child and Adolescent Social Work Journal, 34(6), 597-607. https://doi.org/10.1007/s10560-017-0498-0.

Mihara, S., \& Higuchi, S. (2017). Cross-sectional and longitudinal epidemiological studies of Internet gaming disorder: A systematic review of the literature. Psychiatry and Clinical Neurosciences, 71, 425-444. https://doi.org/10.1111/pcn.12532. 
Na, E., Choi, I., Lee, T. H., Lee, H., Rho, M. J., Cho, H., Jung, D. J., \& Kim, D. J. (2017). The influence of game genre on Internet gaming disorder. Journal of Behavioral Addictions, 6(2), 248-255. https://doi.org/10.1556 /2006.6.2017.033.

Nussbaumer-Streit, B., Mayr, V., Dobrescu, A. I., Chapman, A., Persad, E., Klerings, I., Wagner, G., Siebert, U., Christof, C., Zachariah, C., \& Gartlehner, G. (2020). Quarantine alone or in combination with other public health measures to control COVID-19: A rapid review. Cochrane Database of Systematic Reviews, 4, CD013574. https://doi.org/10.1002/14651858.CD013574.

Nuyens, F., Kuss, D. J., Lopez-Fernandez, O., \& Griffiths, M. D. (2019). The experimental analysis of nonproblematic video gaming and cognitive skills: A systematic review. International Journal of Mental Health and Addiction, 17, 389-414. https://doi.org/10.1007/s11469-018-9946-0.

Pakpour, A. H., \& Griffiths, M. D. (2020). The fear of COVID-19 and its role in preventive behaviors. Journal of Concurrent Disorders, 2(1), 58-63.

Pfefferbaum, B., \& North, C. S. (2020). Mental health and the Covid-19 pandemic. The New England Journal of Medicine. https://doi.org/10.1056/NEJMp2008017.

Reblin, M., \& Uchino, B. (2008). Social and emotional support and its implication for health. Current Opinion in Psychiatry, 21(2), 201-205. https://doi.org/10.1097/yco.0b013e3282f3ad89.

Russoniello, C., O’Brien, K., \& Parks, M. J. (2009). The effectiveness of casual video games in improving mood and decreasing stress. Journal of Cyber Therapy and Rehabilitation, 2(1), 53-66.

Şalvarlı, Ș. İ., \& Griffiths, M. D. (2019). Internet gaming disorder and its associated personality traits: A systematic review using PRISMA guidelines. International Journal of Mental Health and Addiction. https://doi.org/10.1007/s11469-019-00081-6.

Siedlecki, K. L., Salthouse, T. A., Oishi, S., \& Jeswani, S. (2014). The relationship between social support and subjective well-being across age. Social Indicators Research, 117(2), 561-576. https://doi.org/10.1007 /s11205-013-0361-4.

Stavropoulos, V., Dumble, E., Cokorilo, S., Griffiths, M. D., \& Pontes, H. M. (2019). The physical, emotional, and identity user-avatar association with disordered gaming: A pilot study. International Journal of Mental Health and Addiction. https://doi.org/10.1007/s11469-019-00136-8.

Terry, M., \& Malik, A. (2018). Video gaming as a factor that affects academic performance in grade nine. Retrieved June 24, 2020, from: https://files.eric.ed.gov/fulltext/ED583492.pdf.

Turel, O., Romashkin, A., \& Morrison, K. M. (2017). A model linking video gaming, sleep quality, sweet drinks consumption and obesity among children and youth. Clinical Obesity, 7(4), 191-198. https://doi. org/10.1111/cob.12191.

Whiteford, G. (2000). Occupational deprivation: Global challenge in the new millennium. British Journal of Occupational Therapy, 63(5), 200-204. https://doi.org/10.1177/030802260006300503.

World Health Organization (2020). Coronavirus disease (Covid-19) pandemic. Retrieved June 24, 2020, from: https://www.who.int/emergencies/diseases/novel-coronavirus-2019

Xiang, Y.-T., Yang, Y., Li, W., Zhang, L., Zhang, Q., Cheung, T., \& Ng, C. H. (2020). Timely mental health care for the 2019 novel coronavirus outbreak is urgently needed. The Lancet Psychiatry, 7(3), 228-229. https://doi.org/10.1016/S2215-0366(20)30046-8.

Zirek, E., Mustafaoglu, R., Yasaci, Z., \& Griffiths, M. D. (2020). A systematic review of musculoskeletal disorders related to mobile phone usage. Musculoskeletal Science and Practice, 49, 102196. https://oi. org/10.1016/j.msksp.2020.102196.

Publisher's Note Springer Nature remains neutral with regard to jurisdictional claims in published maps and institutional affiliations. 